\title{
Give me a kiss! An integrative rehabilitative training program with motor imagery and mirror therapy for recovery of facial palsy
}

\author{
Teresa PAOLUCCI ${ }^{1}{ }^{*}$, Alessia CARDAROLA ${ }^{2}$, Paola COLONNELLI ${ }^{1}$, \\ Giorgia FERRACUTI 1, Roberta GONNELLA ${ }^{3,4}$, Massimiliano MURGIA 1, Valter SANTILLI 2, \\ Marco PAOLONI ${ }^{2}$, Andrea BERNETTI ${ }^{2}$, Francesco AGOSTINI ${ }^{2}$, Massimiliano MANGONE 2
}

${ }^{1}$ Unit of Physical Medicine and Rehabilitation, Umberto I Polyclinic Hospital, Sapienza University, Rome, Italy; ${ }^{2}$ Department of Anatomy, Histology, Forensic Medicine and Orthopedics, Sapienza University, Rome, Italy; ${ }^{3}$ Department of Experimental Medicine, Sapienza University, Rome, Italy; ${ }^{4}$ Istituto Pasteur Italia - Fondazione Cenci Bolognetti, Rome, Italy

*Corresponding author: Teresa Paolucci, Unit of Physical Medicine and Rehabilitation, Umberto I Polyclinic Hospital, Sapienza University, Rome, Italy. E-mail: teresapaolucci@hotmail.com

\section{A B S T R A C T}

BACKGROUND: Peripheral facial nerve palsy (FNP) can have various causes, such as Bell's palsy or after surgery for acoustic neuroma. Rehabilitation is often required but there is no evidence that any rehabilitation approach is more efficacious than another.

AIM: The purpose of this research was to determine the effects of neurocognitive-rehabilitative approach through mirror-therapy (MT) and motor-imagery (MI), integrated into the traditional rehabilitation with mime-therapy and myofascial-approach.

DESIGN: This study was designed as a double-blind, randomized, controlled trial.

SETTING: This study took place from January 2016 to June 2018 at the Unit of Physical Medicine and Rehabilitation of Umberto I Polyclinic Hospital, Rome, Italy.

POPULATION: Twenty-two patients were randomized into two groups: the mirror therapy group $(\mathrm{N} .=11$, MT and MI) and the traditional rehabilitation group ( $\mathrm{N} .=11$, mime-therapy and a myofascial-approach).

METHODS: Outcome assessments were performed before treatment (T0), after one month (T1=10 session, twice/week), after the second and third months (T2=10 twice/week +5 of MT $+\mathrm{MI}$ one/week and T3=10 twice/week +5 of MT+MI 1/week), and at the 4-week follow-up (T4=2 months follow-up).

RESULTS: The analysis of the functional evaluations show that both groups experienced progressive improvement T0 to T3, with stabilization of the results at the follow-up. There was a significant difference in House-Brackmann-Scale scores between T0 and follow-up in favor of the experimental group. In terms of quality of life (FaCE scale), total scores and social function items improved in both groups from T0 to T3. The experimental group obtained better results with regard to quality of life and emotional depression.

CONCLUSIONS: The integrated use of MT and MI is efficacious in the rehabilitation of FNP, improving facial physical function. Further studies are needed to determine the predictive factors of the recovery of facial mimic.

CLINICAL REHABILITATION IMPACT: The ability of patients with unilateral facial paralysis to recognize and appropriately judge facial expressions and perceive the judgments of others remains underexplored. The likelihood of recovering near-normal facial-function after grade VI facial paralysis is low. Procedures, such as the immediate repair of the facial nerve with an interposed donor graft, might improve facial function in patients with partially injured facial nerves.

(Cite this article as: Paolucci T, Cardarola A, Colonnelli P, Ferracuti G, Gonnella R, Murgia M, et al. Give me a kiss! An integrative rehabilitative training program with motor imagery and mirror therapy for recovery of facial palsy. Eur J Phys Rehabil Med 2020;56:58-67. DOI: 10.23736/S19739087.19.05757-5)

KEY WORDS: Neurocognitive disorders; Rehabilitation; Facial nerve diseases; Facial paralysis.

Deripheral facial nerve palsy (FNP) can have various causes, such as Bell's palsy, which is the most common cause (approximately three-fourths of all cases).
Among secondary causes, tumors and the adverse effects of surgery for tumor pathologies, such as acoustic neuroma and facial nerve schwannoma, are the most prevalent. ${ }^{1}$ 


\section{COPYRIGHT $^{\odot} 2020$ EDIZIONI MINERVA MEDICA}

The prognosis for FNP is complete recovery in roughly $80 \%$ of cases with Bell's palsy, whereas $15 \%$ experiences some type of permanent nerve damage, with the remaining 5\% enduring severe sequelae. In the secondary forms of FNP, the prognosis is worse and is linked to the type of tumor and surgical technique. ${ }^{2-4}$ Immediately after removal a vestibular schwannoma or neuroma of the acoustic nerve, various degrees of facial nerve palsy arise in $20 \%$ to $70 \%$ of patients can occur and based on a survey by the Acoustic Neuroma Association, facial dysfunction is a significant morbidity, specifically with respect to large tumors. ${ }^{5}$ Sure, physical therapy improves functional outcomes for individuals with postoperative changes in facial motor function after facial reanimation surgery. ${ }^{6}$ Then, rehabilitation is important in the management of FNP, for which physical therapy programs with various strategies have been applied, such as exercise therapy, electrotherapy, massage, lymph drainage, and biofeedback therapy. ${ }^{7}$ There is no evidence that any particular rehabilitation is more efficacious than another; conversely, certain treatments have adverse aspects, such as oral-ocular synkinesis. ${ }^{8}$ In association with asymmetry and contracture, synkinesis could be an important consequence of FNP, because they have negative psychosocial effects on patients, for which Electromyography Biofeedback (EMG-BFB) is a suitable exercise therapy. ${ }^{9}$ Also, the communicative function of the facial expressions of emotion is critical to healthy social interactions: emotional and communicative disorders can develop in patients with FNP in the chronic stage of disease, including emotion-recognition impairments. ${ }^{10}$ To this end, FNP should be treated in a multidisciplinary setting, in which physical therapy (specifically, neuromuscular retraining) and psychological and medical or surgical interventions are integrated. ${ }^{11}$ In particular, mime therapy is effective in patients with FNP, for whom the benefits remain stable at long follow-ups (over 1 year), improving facial symmetry and reducing the severity of paresis. ${ }^{12,} 13$ Several studies have reported that a facial muscle exercise program that includes facial massage and a myofascial approach is an effective intervention for improving facial muscle function and decreasing depression in patients with FNP. ${ }^{14}$ For secondary forms of FNP, such as after surgery for acoustic neuroma, several rehabilitative procedures are often required when inadequate function or poor cosmetic results are obtained. Primary nerve repair or facial-hypoglossal anastomosis provides better rehabilitative results than dynamic and static procedures. ${ }^{15}$ Thus, FNP is a significant problem in patients after surgery for acoustic neuroma, significantly lower- ing his quality of life. ${ }^{16}$ Because there is no evidence of the superiority of any rehabilitative treatment compared with another in the recovery of FNP, the purpose of this research was to determine the effects of a neurocognitive approach through mirror therapy (MT) and motor imagery (MI), integrated into the traditional rehabilitative method with mime therapy and a myofascial approach.

MT is a safe and easy-to-use treatment for the recovery of stroke patients and phantom limb pain. ${ }^{17}$ Further, based on the hypothesis by Ramachandran with regard to overcoming the "perceptual and visual discrepancy" between movement and the perception of the movement, MT can be a good method to other neurological conditions. ${ }^{18}$ The use of MI, which is always used in rehabilitative pathways with MT before rehabilitative exercises are initiated, allows the patient to consciously perceive a movement without actually reconstructing the bridge between "perception and movement and perceptual experience is organized around expectations": MI aims to recompose the correct coherent information. ${ }^{19}$ Thus, the aim of the study is to measure the effect of the integration of MT and MI in the standard rehabilitation for FNP versus standard rehabilitation alone. The primary outcome was the recovery of facial paralysis with attention regard to preventing dyskinesia and synkinesis, and the secondary outcome was the recovery in quality of life. ${ }^{20}$

\section{Materials and methods}

This study was designed as a double-blind, randomized, controlled trial and took place from January 2016 to June 2018. Thirty-two patients who were diagnosed with FNP after surgery for acoustic neuroma were referred to a physiatrist by the neurosurgeon. Twenty-two $(\mathrm{N} .=22)$ patients were enrolled, because they met the inclusion criteria and agreed to participate, and were then randomized into two groups according to a computer-generated simple randomization list at a 1:1 ratio (MATLAB R2007b ${ }^{\circledR}$, The MathWorks, Inc.): mirror therapy $(\mathrm{N} .=11)$ and control $(\mathrm{N} .=11)$ (Figure 1).

The inclusion criteria were: unilateral facial palsy after surgery for acoustic neuroma, less than 12 months elapsed from surgery, age 18 to 60 years, House-Brackmann Scale (HBS) $\geq$ III. ${ }^{21}$

The exclusion criteria were: pregnant women, Bell facial palsy, the presence of autoimmune or hematologic disease, pharmacological and psychological treatment for a psychiatric disorder, other tumors, major neurological problems, and diabetes. The pharmacological therapeutic regimen must have been stable for at least 3 months before the pa- 


\section{COPYRIGHT $^{(\odot)} 2020$ EDIZIONI MINERVA MEDICA}

PAOLUCCI

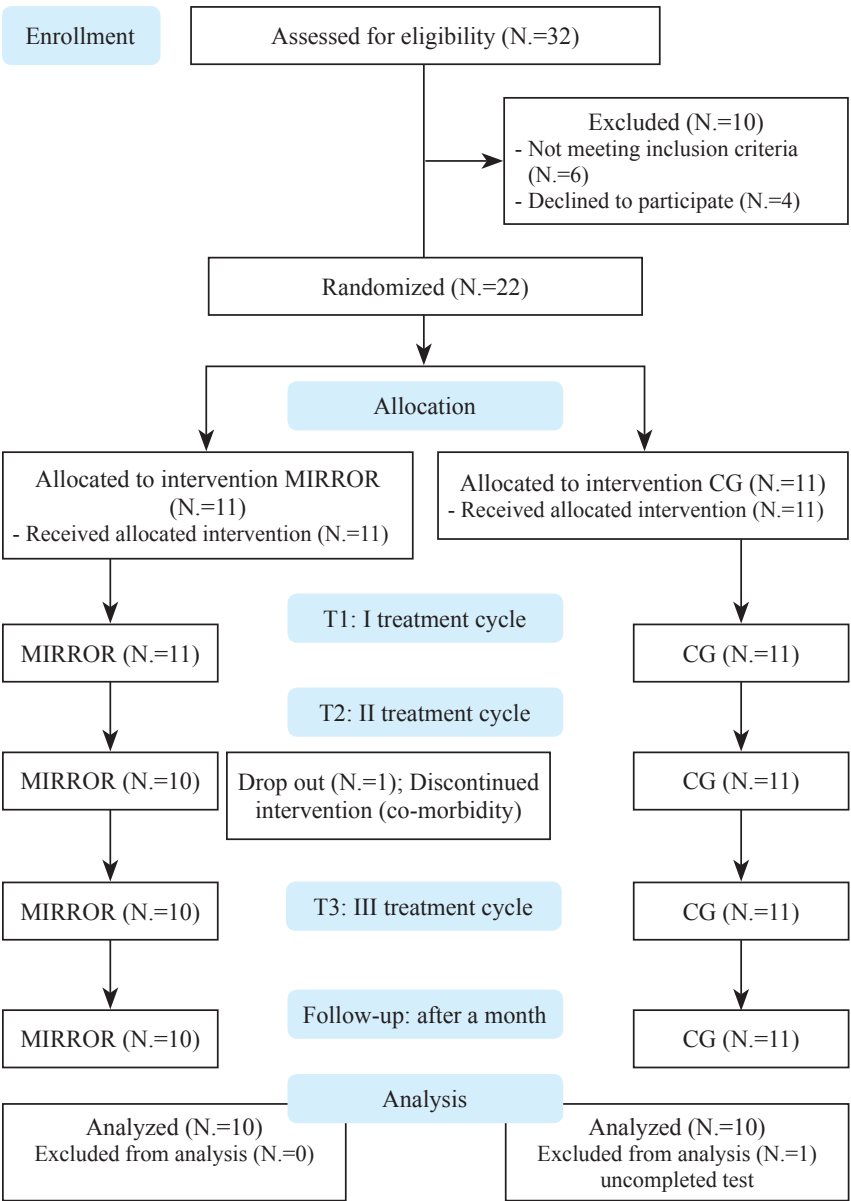

Figure 1.-Flow chart of the study.

tient began treatment. No new medications or other rehabilitation approaches were undertaken during this study.

The patients were informed about the scope and procedures of the study per the Declaration of Helsinki, and their written consent for participation in the research project was obtained.

For concealment of the allocation, a physiatrist identified the patients who were sent by the neurosurgeon and who met the inclusion and exclusion criteria and obtained signed informed consent forms for study participation. The patients, the physiatrist who enrolled them, and the researcher (psychologist or physiatrist) who administered the evaluation scales were blinded to the rehabilitative treatment.

This study protocol was developed in accordance with the Consolidated Standards of Reporting Trials (CONSORT) guidelines ${ }^{22}$ and was approved by the Ethics and
Experimental Research Committee of Sapienza University, Rome, Italy (Protocol Number 4949-2018).

Outcome assessments were performed for each group before treatment $(\mathrm{T} 0=$ baseline $)$, at the end of the first month of rehabilitative treatment $(\mathrm{T} 1=10$ sessions twice for week), after the second and third months of rehabilitative treatment $(\mathrm{T} 2=10$ sessions twice for week plus 5 sessions of MT+MI one for week and T3 $=10$ sessions twice for week plus 5 sessions of MT+MI 1 for week), and at the 4-week follow-up (T4 = follow-up, after 2 months).

\section{Clinical evaluation scales}

\section{House-Brackmann scale}

The House-Brackmann Scale (HBS) is one of several analysis tools that have been developed to quantify facial function and provide reproducible information in measuring the global degree of paresis and paralysis. It is a widely accepted system and is simple, sensitive, accurate, and reliable, grading facial function in 6 stages, from normal (HB I) to total paralysis (HB VI). ${ }^{20,23}$

\section{Sunnybrook Facial Grading System}

The Sunnybrook Facial Grading System (SFGS) focuses on facial asymmetries and the presence or absence of synkinesis. Facial symmetry is evaluated, comparing the paretic half of the face with the nonparetic side during rest and during voluntary movements, generating a single composite score from 0 to 100 .

First, the physician assesses the symmetry of the eye, cheek (nasolabial fold), and mouth at rest. The options under each item are assigned a value of $0-2$, and the sum is attributed a weighted factor of 5 . Then, the physician rates facial movements during 5 standard facial expressions on a scale of 1-5 ( $1=$ no movement, $2=$ slight movement, 3 $=$ mild excursion, $4=$ near normal movement, and $5=$ normal movement). These values are summed and multiplied by 4 . In the third step, the physician grades the severity of synkinesis on a 4-point scale ( $1=$ none, $2=$ mild, 3 $=$ moderate, and $4=$ severe) during the 5 expressions, as in the second step. The totaled synkinesis score is given a weighted factor of 1 . The overall score is the weighted sum of the three parts. ${ }^{24}$

\section{Facial Clinimetric Evaluation Scale}

The Facial Clinimetric Evaluation Scale (FaCE) is a patient-based instrument that measures facial impairment and disability in evaluating quality-of-life issues that are caused by facial disability. ${ }^{25}$ This questionnaire consists of 


\section{COPYRIGHT $^{\circledR} 2020$ EDIZIONI MINERVA MEDICA}

15 questions on a 5-point Likert Scale and comprises 6 domains: facial movement, facial comfort, oral function, eye comfort, lacrimal control, and social function. Total and domain scores range from 0 (worst) to 100 (best). This scale has been used in several studies on patient satisfaction following treatment. ${ }^{26,27}$

\section{Beck Depression Inventory Scale}

The 21-item Beck Depression Inventory (BDI) consists of four statements that describe increasing intensities of depressive symptoms and includes somatic and cognitiveaffective symptoms; each item is divided into a scale from 0 to 3 , reflecting the patient's feelings in the previous 2 weeks. A total score of all 21 items is generated; score of 14 or above is indicative of depressive symptoms. ${ }^{28} \mathrm{De}$ pressive symptoms were categorized as: minimal-moderate (range 14-19), moderate-severe (range 20-29), and severe (range 30-63). ${ }^{29}$

\section{Rehabilitation treatment}

All patients underwent rehabilitation for a total of 3 months. During the first month, the sessions were held 3 times per week for the first 2 weeks, followed by twice per week (for a total of 10 sessions), lasting from 30 minutes to 45 minutes, depending on the patient's capacity to concentrate and fatigue. After the first month, rehabilitation was administered twice per week, for 45 to 60 minutes (for other 20 sessions).

The patient received an illustrated pamphlet with specific exercises that could be repeated at home during the treatment period (with and without a mirror), according to the residual facial functional capacity and the progression of recovery of facial palsy-smile, give a kiss with facilitation and reinforcement maneuvers, blow into a straw, inflate the cheeks, curl the nose, gently close the eyes with the fingers, and raise the eyebrows. At the end of the third month of the outpatient rehabilitative treatment, patients continued to perform the exercises at home per the handbook twice weekly for an additional month, after which they underwent a clinical check-up to evaluate the functional and mimic muscle recovery of the paresis.

The physiotherapists who were dedicated to this project had extensive experience in the rehabilitation of peripheral paresis of the facial nerve and were trained in the use of mirror therapy and motor imagery exercises. Patients in both groups participate in 4-6 psychological counseling sessions during the rehabilitative intervention to aid in its emotional and communicative aspects.

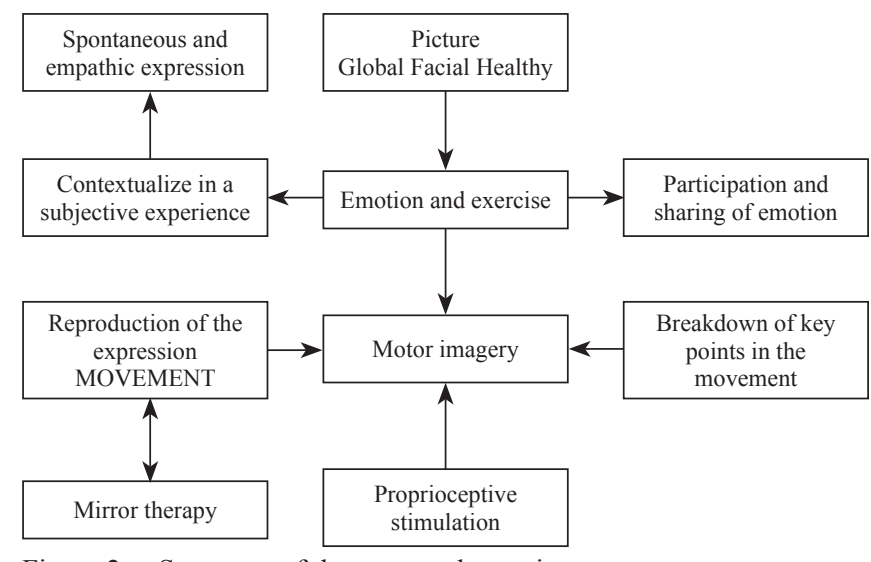

Figure 2.- Summary of the proposed exercise.

Experimental group: mirror therapy and motor imagery

In the experimental group, patient performed an additional weekly session of mirror therapy, from the beginning of the rehabilitation, using specific software (IDIBELL: idibell.cat/en/node/257) to create real-time symmetric facial images and record data to monitor their rehabilitative treatment (Figure 2) and motor imagery exercises.

The emotional facial expressions that the patients were requested to perform were as follows per Osgood for nonverbal communication: ${ }^{30}$ happiness, sadness, interest, disgust, fear, anger, and surprise. Much importance has been placed on the qualitative aspects of the relationship between the physiotherapist and patient with respect to language, such much metaphors were used during the session, including "send me a kiss" and "give me a wink" to increase the latter's understanding of the exercise with empathy. Each session lasted from 45 minutes to $60 \mathrm{~min}$ utes, depending on the patient's ability to maintain attention and cognitive fatigue, respecting rest breaks.

Using the software, the patient as a real mirror box, can view a duplicate of the non-paretic face on a computer screen to have a representation of his complete prelesional face. At this point, the therapist asks the patient to imagine himself winking, for example, imagining himself in a familiar and pleasant social context; then, the patient mentally represents, with his eyes closed, the movement of decomposing the identified key points, without producing any movement. Subsequently, the patient is asked to note the therapist's touch at certain key points of the facial ocular area to better perceive the movement that will be performed and retain the memory of the kinesthetic information that is perceived. At this point, the patient can 


\section{COPYRIGHT $^{\odot} 2020$ EDIZIONI MINERVA MEDICA}

PAOLUCCI
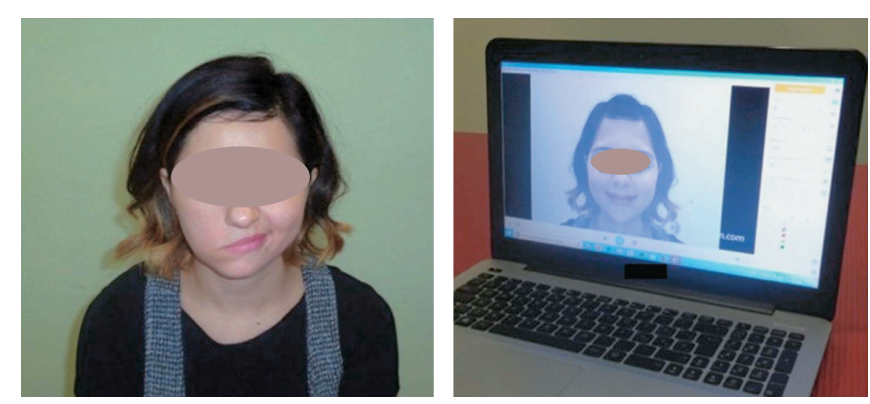

Figure 3.- Mirror therapy and motor imagery exercises.

perform the movement, receiving the image from the digital duplication of the half healthy face as visual feedback (Figure 3).

\section{Control group: traditional rehabilitation}

The traditional rehabilitation treatment includes mime therapy (MT) ${ }^{31-33}$ and then an initial session on information about the treatment and prognosis with the physiatrist; self-massage of the face and neck; breathing and relaxation exercises; exercises to coordinate both sides and reduce synkinesis and for eye and lip closure per the myofascial approach to rehabilitation; letter and word exercises; and expressive exercises.

Myofascial release (MFR) is a form of manual therapy that involves the application of a low-load, long-duration stretch to the myofascial complex, intended to restore optimal length, decrease pain, and improve function. ${ }^{14}$ The patient is placed in a supine position, with his head resting comfortably, and the therapist is usually situated at the head of the couch and, for certain maneuvers, laterally to the injured side.

Then, the therapist performs "myofascial induction" specifically for the ocular areas (orbicular muscle of the eye, major and minor zygomatic muscle, and oral orbicular muscle): initially, 1) longitudinal induction maneuvers of the ocular region, 1a) transverse induction maneuvers of the ocular region in association with 2) transverse induction of the zygomatic region and 2a) longitudinal sliding of the zygomatic region. Next, for the lower part of the face (temporal muscle, masseter muscle, and external and internal pterygoid muscles): 1) deep myofascial induction maneuvers of the temporal muscle in the first and second phases, 1a) decompression of the temporal muscles; 2) longitudinal and transversal induction of the masseter muscle, and 2a) post-isometric induction of the masseter by intra-buccal technique. In this phase, the patient must open his mouth softly, and the therapist places
FACIAL PALSY REHAB WITH MOTOR IMAGERY AND MIRROR THERAPY
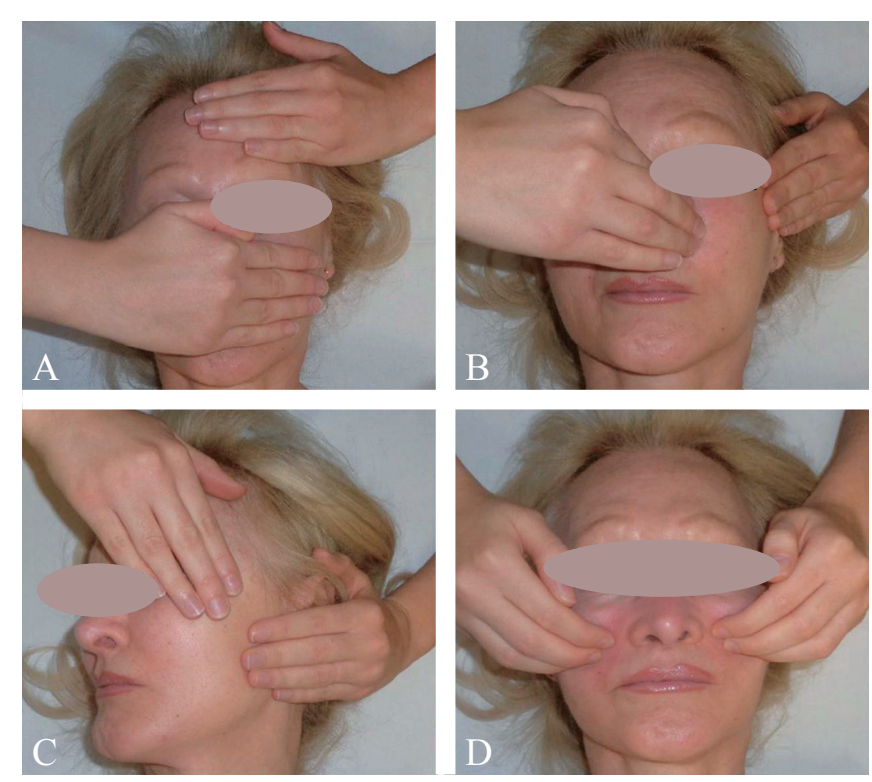

Figure 4.-A) Longitudinal induction maneuvers of the ocular region; B) Transverse induction maneuvers of the ocular region in association with transverse induction of the zygomatic region (C) and longitudinal sliding of the zygomatic region (D).

his thumbs in the mouth on the upper part of the lower molars; then, the patient makes an isometric contraction for several seconds with both masseter muscles against the resistance that is applied by the therapist. In the relaxation phase, the therapist performs three consecutive myofascial inductions. With regard to the masseter muscle, intrabuccal myofascial induction of the external and internal pterygoid muscles is performed. Thus, the session is completed with myofascial induction of the tongue muscles and the orbicular muscles of the mouth in the transverse and longitudinal directions (Figure 4).

Especially in the early stages of treatment and during the first period, to avoid synkinesis, the exercise is performed passively, and the patient is not required to recruit any muscles. Only later, and always preventing synkinesis, is the patient required to actively recruit the paretic muscles.

\section{Calculation of sample size}

The sample size was determined, considering functional recovery of the facial palsy as the main outcome per the Sunnybrook Facial Grading System (SFGS). ${ }^{34}$

The SFGS focuses on the facial asymmetries and the presence or absence of synkinesis. Facial symmetry is evaluated, comparing the paretic versus non paretic side of the face during rest and voluntary movements, form- 


\section{COPYRIGHT $^{\circledR} 2020$ EDIZIONI MINERVA MEDICA}

ing a single composite score from 0 to 100 . Student $t$-test was used for independent variables, considering a power of $80 \%, \alpha$ significance of 0.05 , a mean difference between the two groups of 20 , and a standard deviation of \pm 18.2 for the experimental group (SG) and \pm 16.2 for the control group. ${ }^{12}$ With these parameters, assuming a dropout rate of $10 \%$, the required sample size was 10 patients per group, as calculated using $\mathrm{G}^{*}$ Power v. 3.1.9.2.

\section{Statistical analysis}

Values are expressed as median and IQR (interquartile range) for continuous variables and proportion for categorical variables, as appropriate. Demographic and clinical data at baseline included the following: sex (female or male), age, Body Mass Index (BMI), HBS grade, SFGS score, Face score, and BDI score. Differences in baseline characteristics between the two treatment groups (experimental group and traditional treatment group) were analyzed by Fisher Exact test, or Mann-Whitney U-test, as appropriate.

The analysis of time difference in the two groups was performed through a Friedmann analysis for repeated analyzes to determine if there were differences in the different evaluation times in the two groups. A subsequent analysis for each parameter, a pairwise comparison, was performed with a Bonferroni correction. The Mann-Whitney U-test was used for all the parameters studied to evaluate the time differences between groups and the variations $(\Delta)$ between $\mathrm{T} 0$ and $\mathrm{T} 1, \mathrm{~T} 1$ and $\mathrm{T} 2, \mathrm{~T} 2$ and $\mathrm{T} 3, \mathrm{~T} 3$ and $\mathrm{FU}$ and $\mathrm{T} 0$ and FU between the two groups were compared.

\section{Results}

During rehabilitation treatment period, one patient dropped out in the experimental Group for discontinued intervention; instead in the control Group 1 patient test was excluded by the analysis because incomplete. Then the data of 10 patients for group were analyzed.

The two groups were match for age, BMI and time from surgery (months) as shown in Table I. No subject reported exacerbations of symptoms during or after rehabilitation intervention.

\section{Within-group analysis}

All the parameters analyzed change significantly in the two groups (Table II). The analysis of the functional evaluations, performed according to the HBS and SFGS, showed that both groups experienced a global and progressive improvement from $\mathrm{T} 0$ to $\mathrm{T} 3$, with stabilization of the
TABLE I.-Sample characteristics.

\begin{tabular}{lccc}
\hline Variables & EG $(\mathrm{N} .=10)$ & $\mathrm{CG}(\mathrm{N} .=10)$ & Overall (N.=20) \\
\hline Gender & & & \\
Male & $5(50 \%)$ & $6(60 \%)$ & $11(55 \%)$ \\
Female & $5(50 \%)$ & $4(40 \%)$ & $9(45 \%)$ \\
Median age, years & $49(29-66)$ & $48.5(26-52)$ & $49(26-65)$ \\
$\quad$ Median BMI, kg/m² & $21(18-26)$ & $21.5(18-28)$ & $21(18-28)$ \\
Marital status & & & \\
$\quad$ Unmarried & $1(10 \%)$ & $4(40 \%)$ & $5(25 \%)$ \\
Married & $5(50 \%)$ & $5(50 \%)$ & $10(50 \%)$ \\
Divorced & $4(40 \%)$ & $1(10 \%)$ & $5(25 \%)$ \\
$\quad$ Widow & 0 & 0 & 0 \\
Educational level & & & \\
$\quad$ Primary school & 0 & 0 & 0 \\
Middle school & 0 & $1(10 \%)$ & $1(5 \%)$ \\
High school & $6(60 \%)$ & $6(60 \%)$ & $12(60 \%)$ \\
$\quad$ Graduation & $4(40 \%)$ & $3(30 \%)$ & $7(35 \%)$ \\
Months from onset of FP, & & & \\
months & & & \\
Left & $6(60 \%)$ & $5(50 \%)$ & $11(55 \%)$ \\
$\quad$ Right & $4(40 \%)$ & $5(50 \%)$ & $9(45 \%)$ \\
Median (range) & $3.75(1-24)$ & $4.4(1-24)$ & \\
\hline EG: expen & &
\end{tabular}

EG: experimental group; CG: control group.

results at the follow-up (HBS, at T0-FU for EG $\mathrm{P}=0.000$ and for $\mathrm{CG} P=0.000$; SFGS at T0-FU for $\mathrm{EG} \mathrm{P}=0.000$ and for $C G \mathrm{P}=0.000$ ). This trend was statistically significant in both groups between T0 and T2, T3 and the follow-up, and $\mathrm{T} 1$ and the follow-up, more so than between the intermediate points (T2-T3, T2-FU), $\mathrm{T} 0$ and $\mathrm{T} 1$, and $\mathrm{T} 3$ and the follow-up.

The quality of life per the FACE scale total scores and social function item, improved in both groups from $\mathrm{T} 0$ to $\mathrm{T} 3$ in the total score, stabilizing at the follow-up (FaCE Tot at T0-FU for EG $\mathrm{P}=0.000$ and for $\mathrm{CG} \mathrm{P}=0.000 ; \mathrm{FaCE}$-sf T0-FU for $\mathrm{EG} P=0.043$ and for $\mathrm{CG} P=0.047$ ). This pattern was significant in both groups between $\mathrm{T} 0$ and $\mathrm{T} 3$ and at the follow-up between $\mathrm{T} 1$ and $\mathrm{T} 3$ and at the follow-up, compared with the intermediate times (T2-T3, T2-FU), between $\mathrm{T} 0$ and $\mathrm{T} 1$, and between $\mathrm{T} 3$ and the follow-up. Both groups improved for BDI from T0 to T3, which stabilized at the follow-up. This change was significant in both groups between T0-T3, T0-follow-up, T1-T3, and T1 and the follow-up, versus T0-T1, T0-T2, T1-T2, T2-T3, and $\mathrm{T} 3$ and the follow-up (BDI at T0-FU for EG $\mathrm{P}=0.029$ and for $\mathrm{CG} P=0.196$ ) (Table II).

Between-group analysis

Over time, there was a significant difference in HBS scores between $\mathrm{T} 0$ and the follow-up in favor of the EG $(\Delta \mathrm{T} 0-\mathrm{FU}$ $\mathrm{P}=0.043)$. The $\mathrm{FaCE}$ tot improved significantly between 


\section{COPYRIGHT $^{(} 2020$ EDIZIONI MINERVA MEDICA}

PAOLUCCI

FACIAL PALSY REHAB WITH MOTOR IMAGERY AND MIRROR THERAPY

TABLE II.—Result of scale evaluation.

\begin{tabular}{|c|c|c|c|c|c|c|c|c|c|c|}
\hline \multirow{2}{*}{ Comparisons } & \multicolumn{2}{|c|}{ HBS } & \multicolumn{2}{|c|}{ SFGS } & \multicolumn{2}{|c|}{ BDI } & \multicolumn{2}{|c|}{ FaCE total } & \multicolumn{2}{|c|}{ FaCE-sf } \\
\hline & EG & $\mathrm{CG}$ & EG & CG & EG & CG & EG & $\mathrm{CG}$ & EG & $\mathrm{CG}$ \\
\hline \multicolumn{11}{|c|}{ Within-group timepoint comparisons } \\
\hline $\mathrm{T} 0$ & $5(2)$ & $4(1)$ & $9(20)$ & $10.5(17)$ & $14(8)$ & $13.5(9)$ & $33.3(13.3)$ & $25.8(13.7)$ & $31.25(12.5)$ & $18.75(12.5)$ \\
\hline $\mathrm{T} 1$ & $3(1)$ & $3(1)$ & $54(23)$ & 37 (19) & $10(5)$ & $11.5(8.5)$ & $41.6(21.7)$ & $37.45(21.68)$ & $31.25(18.75)$ & $34.37(53.12)$ \\
\hline $\mathrm{T} 2$ & $2(1)$ & $3(0)$ & $84(21)$ & $67(19.5)$ & $9(4)$ & $10.5(8.25)$ & $55(20)$ & $55.8(13.3)$ & $56.25(25)$ & $46.87(32.81)$ \\
\hline $\mathrm{T} 3$ & $2(0)$ & $2(1)$ & $92(12)$ & $86(9.5)$ & $6(3)$ & $10(7.75)$ & $78.3(5)$ & $68.3(12.92)$ & $75(18.75)$ & $56.25(23.43)$ \\
\hline $\mathrm{FU}$ & $2(0)$ & $2(1)$ & $92(8)$ & $86(9.5)$ & $5(2)$ & $9.5(5.25)$ & $86.6(10)$ & $68.3(11.62)$ & $81.25(18.75)$ & $55.25(17.19)$ \\
\hline \multicolumn{11}{|c|}{ Post-hoc comparisons } \\
\hline Р T0-T2 & $0.014 *$ & $0.024 *$ & $0.029 *$ & $0.047^{*}$ & $0.005 * *$ & $0.009 * *$ & 0.091 & $0.024 *$ & $0.001 * *$ & $0.011 * *$ \\
\hline Р T0-T3 & $0.000 * *$ & $0.000 * *$ & $0.000 * *$ & $0.000 * *$ & $0.000 * *$ & $0.000 * *$ & $0.001 * *$ & $0.000^{*}$ & $0.000 * *$ & $0.001 * *$ \\
\hline P T0-FU & $0.000^{* *}$ & $0.000 * *$ & $0.000^{* *}$ & $0.000 * *$ & $0.029 *$ & 0.196 & $0.000 * *$ & $0.000^{*}$ & $0.043^{*}$ & $0.047^{*}$ \\
\hline P T1-T3 & $0.037 *$ & $0.015^{*}$ & 0.22 & $0.005 * *$ & $0.000 * *$ & $0.011 * *$ & $0.046^{*}$ & $0.047^{*}$ & $0.003 * *$ & $0.004 * *$ \\
\hline P T1-FU & $0.037^{*}$ & $0.015 * *$ & $0.08^{*}$ & $0.003 * *$ & $0.005^{* *}$ & $0.009 * *$ & $0.001 * *$ & $0.001 * *$ & $0.001 * *$ & $0.011 * *$ \\
\hline \multicolumn{11}{|c|}{ Between-group timepoint comparisons } \\
\hline $\mathrm{T} 0-\mathrm{T} 1$ & \multicolumn{2}{|c|}{$0.053 *$} & \multicolumn{2}{|c|}{0.720} & \multicolumn{2}{|c|}{0.661} & \multicolumn{2}{|c|}{0.400} & \multicolumn{2}{|c|}{0.211} \\
\hline $\mathrm{T} 1-\mathrm{T} 2$ & \multicolumn{2}{|c|}{0.400} & \multicolumn{2}{|c|}{1.000} & \multicolumn{2}{|c|}{0.211} & \multicolumn{2}{|c|}{0.720} & \multicolumn{2}{|c|}{0.400} \\
\hline $\mathrm{T} 2-\mathrm{T} 3$ & \multicolumn{2}{|c|}{0.497} & \multicolumn{2}{|c|}{0.661} & \multicolumn{2}{|c|}{0.065} & \multicolumn{2}{|c|}{0.133} & \multicolumn{2}{|c|}{$0.05^{*}$} \\
\hline T3-FU & \multicolumn{2}{|c|}{1.000} & \multicolumn{2}{|c|}{0.661} & \multirow{2}{*}{\multicolumn{2}{|c|}{0.211}} & \multirow{2}{*}{\multicolumn{2}{|c|}{$0.004 *$}} & \multicolumn{2}{|c|}{0.356} \\
\hline T0-FU & \multicolumn{2}{|c|}{$0.043 *$} & \multicolumn{2}{|c|}{0.356} & & & & & \multicolumn{2}{|c|}{$0.033^{*}$} \\
\hline
\end{tabular}

Data expressed as median (interquartile range) if not otherwise specified.

HBS: House-Brackmann Scale; SFGS: Sunnybrook Facial Grading System; BDI: Beck Depression Inventory Scale; FaCE: Facial Clinimetric Evaluation Scale; FaCEsf: Facial Clinimetric Evaluation Scale-social function; IQR: range interquartile; EG: experimental group; CG: control group.

$* \mathrm{P}<0.05 ; * * \mathrm{P}<0.01$.

TABLE III.-Between-group statistical analysis.

\begin{tabular}{|c|c|c|c|c|c|c|c|c|c|c|}
\hline \multirow{2}{*}{ Parameters } & \multicolumn{2}{|c|}{ HBS } & \multicolumn{2}{|c|}{ SFGS } & \multicolumn{2}{|c|}{ BDI } & \multicolumn{2}{|c|}{$\mathrm{FaCE}$ total } & \multicolumn{2}{|c|}{ FaCE-sf } \\
\hline & EG & $\mathrm{CG}$ & EG & $\mathrm{CG}$ & EG & $\mathrm{CG}$ & EG & $\mathrm{CG}$ & EG & $\mathrm{CG}$ \\
\hline \multicolumn{11}{|l|}{$\Delta \mathrm{T} 0-\mathrm{T} 1$} \\
\hline Median & $1.5(0 ; 3)$ & $1(0 ; 1)$ & $38.5(4 ; 60)$ & $31(15 ; 47)$ & $-2.5(-5 ; 8)$ & $1.5(-1 ; 2)$ & $14.18(0 ; 25)$ & $12.5(3.3 ; 35.4)$ & $12.5(0 ; 37.5)$ & $3.125(-12.5 ; 75)$ \\
\hline$P$ value & \multicolumn{2}{|c|}{$0.053^{*}$} & \multicolumn{2}{|c|}{0.720} & \multicolumn{2}{|c|}{0.661} & \multicolumn{2}{|c|}{0.400} & \multicolumn{2}{|c|}{0.211} \\
\hline \multicolumn{11}{|l|}{$\Delta \mathrm{T} 1-\mathrm{T} 2$} \\
\hline Median & $1(0 ; 2)$ & $0(0 ; 1)$ & $28(9 ; 60)$ & $30(9 ; 43)$ & $0.5(0 ; 69)$ & $-0.5(-1 ; 2)$ & $13.37(1.6 ; 33.3)$ & $10(0 ; 28.3)$ & $21.85(0 ; 31.25)$ & $6.26(0 ; 31.25)$ \\
\hline$P$ value & \multicolumn{2}{|c|}{0.400} & \multicolumn{2}{|c|}{1.000} & \multicolumn{2}{|c|}{0.211} & \multicolumn{2}{|c|}{0.720} & \multicolumn{2}{|c|}{0.400} \\
\hline$\Delta \mathrm{T} 2-\mathrm{T} 3$ & $0(0 ; 1)$ & $1.5(0 ; 2)$ & $8(0 ; 45)$ & $12.5(4 ; 30)$ & $1(0 ; 6)$ & $2(0 ; 3)$ & $17.5(5 ; 28.3)$ & $10.85(-8.3 ; 30)$ & $21.9(0 ; 31.3)$ & $6.25(0 ; 12.5)$ \\
\hline $\begin{array}{l}\text { Median } \\
\text { P value }\end{array}$ & \multicolumn{2}{|c|}{0.497} & \multicolumn{2}{|c|}{0.661} & \multicolumn{2}{|c|}{0.065} & \multicolumn{2}{|c|}{0.133} & \multicolumn{2}{|c|}{$0.05^{*}$} \\
\hline \multicolumn{11}{|l|}{$\Delta \mathrm{T} 3-\mathrm{FU}$} \\
\hline Median & $0(0 ; 0)$ & $0(0 ; 0)$ & $0(0 ; 8)$ & $0(0 ; 7)$ & $1.5(0 ; 3)$ & $0.5(-1 ; 3)$ & $5.8(0 ; 16.6)$ & $1.65(-3.4 ; 5)$ & $6.25(0 ; 6.25)$ & $3.125(0 ; 6.26)$ \\
\hline$P$ value & \multirow{2}{*}{\multicolumn{2}{|c|}{1.000}} & \multirow{2}{*}{\multicolumn{2}{|c|}{0.661}} & \multicolumn{2}{|c|}{0.211} & \multicolumn{2}{|c|}{$0.004 *$} & \multicolumn{2}{|c|}{0.356} \\
\hline \multicolumn{7}{|l|}{$\Delta \mathrm{T} 0-\mathrm{FU}$} & & & & \\
\hline Median & $2.5(2 ; 4)$ & $2.5(1 ; 3)$ & $74.5(43 ; 96$ & $73.5(57 ; 84)$ & $0.5(-2 ; 15)$ & $3.5(1 ; 9)$ & $50.85(31.6 ; 66.6)$ & $35(15 ; 61.6)$ & $62.5(31.25 ; 75)$ & $18.75(-6.25 ; 75)$ \\
\hline$P$ value & \multicolumn{2}{|c|}{$0.043 *$} & \multicolumn{2}{|c|}{0.356} & \multicolumn{2}{|c|}{$0.017^{* *}$} & \multicolumn{2}{|c|}{$0.043^{*}$} & \multicolumn{2}{|c|}{0.133} \\
\hline
\end{tabular}

HBS: House-Brackmann Scale; SFGS: Sunnybrook Facial Grading System; BDI: Beck Depression Inventory Scale; FaCE: Facial Clinimetric Evaluation Scale; FaCEsf: Facial Clinimetric Evaluation Scale-social function; IQR: range interquartile; EG: experimental group; CG: control group. $* \mathrm{P}<0.05 ; * * \mathrm{P}<0.01$.

$\mathrm{T} 0$ and at the follow-up in the $\mathrm{EG}(\Delta \mathrm{T} 0-\mathrm{FU} \mathrm{P}=0.043)$ and also for FaCE-sf differed significantly between $\mathrm{T} 2$ and $\mathrm{T} 3$ in the $\mathrm{EG}(\Delta \mathrm{T} 2-\mathrm{T} 3 \mathrm{P}=0.05)$. For $\mathrm{BDI}$ between $\mathrm{T} 0$ and the follow-up was observed a reduction of depression in favor of the $\mathrm{EG}(\Delta \mathrm{T} 0-\mathrm{FU} \mathrm{P}=0.017)$. No statistically significant difference was observed for the scale SFGS (Table III).

\section{Discussion}

Our hypothesis was that MT and MI treatment, in addition to traditional rehabilitation (mime therapy and the myofascial approach), would improve the rehabilitation of facial nerve palsy. In this regard, our results were notable: 


\section{COPYRIGHT $^{(\odot)} 2020$ EDIZIONI MINERVA MEDICA}

between groups, during the evaluation times, the EG experienced greater efficacy with respect to the HBS at T0T1 and T0-Tfollow-up, the BDI at T0-Tfollow-up, and the FaCE scale at T0-Tfollow-up.

Moreover, both groups showed good efficacy with the rehabilitation treatment over time regarding the primary and secondary outcomes: the patients experienced greater recovery of facial paralysis, avoiding dyskinesias and synkinesis, and a better quality of life, especially concerning social functions.

MT, which has existed since the 1990s, used initially as a therapy for pain in phantom limb syndrome in amputees. Several years later, this technique began to be used by patients with hemiparesis due to cerebral injuries, and today it has become useful for other pathologies. ${ }^{35}$ Several theories have been postulated to understand the mechanisms of this technique, such as the activation of the mirror neurons circuit and the interpretation of the mirror reflex by the brain as an image that corresponds to the paretic side, activating the injured motor circuits and easing the movement. $36-38$

The MT, and the its association with MI that prompted the patient to imagine the movement before executing it, allowing him/her to perceive the correct movement in the facial paresis through visual feedback by viewing the reflection of the intact face in place of the facial palsy. Each time that the patient attempted to move the paralyzed face, he/she received sensory feedback (through vision and proprioception if necessary with the touch of the hands by physiotherapist), in which the face moved symmetrically.

By overcoming the visual-motor "misperception," the patient did not initiate excessive contraction of the muscles, preventing synkinesis and dyskinesia.

Further, the patient had a more harmonious and pleasant representation of his face, avoiding and containing emotional frustration: FNP causes disfigurements, with cosmetic, functional, and psychological repercussions, and was significantly associated with increased depression and worse QOL scores. In addition, female sex is linked to greater depression scores. 39,40 The EG contained their depressive symptoms better, based on the BDI scale, because mental practice through MI could help reconstruct an esthetically acceptable facial image that gives the patient more time to process the facial damage that is suffered, with less frustration. Several groups have studied MI as a potential tool to examine action representation, because it can provide insights into the processes of action planning and preparation: the data suggest that depressed patients present with specific impairments in mental rotation.

The impaired behavioral performance in processing mental representations is related to depression, and a deficit in mental rotation in depressive patients might be a biomarker for chronic recurrence. ${ }^{41}$ Also, several reports suggest that actual and mental actions trigger similar neural substrates: motor learning via physical practice results in long-term potentiation (LTP) -like plasticity processesnamely, potentiating of M1 and temporary occlusion of additional LTP-like plasticity. ${ }^{42}$ Thus, as evidenced by our results, MT and MI increase the acceptability of the pathology by reducing depressive symptoms (BDI delta T0Follow-up scale $\mathrm{P}=0.043$ ).

FNP negatively affects one's quality of life, in addition to its severe physical symptoms and psychosocial factors. 43

In our EG, patients improved their quality of life greater than in the control group, particularly for social function on the $\mathrm{FaCE}$ scale. Facial paralysis is a significant problem in patients with acoustic neuroma, but often, treatment for facial paralysis is not offered, and even when it is administered, the patient's quality of life remains significantly lower. ${ }^{16}$ Thus, this result encourages us to propose traditional rehabilitative treatment in combination with MT and MI.

The perception of emotions is an important component in enabling humans to participate in social interactions in everyday life. ${ }^{44}$ We hypothesize that improving emotional and communicative aspects positively influences quality of life, as seen in the EG, who performed MI exercises that were based on interpreting, recognizing, and feeling emotions. This area should be examined in greater detail in larger patient groups.

The ability of patients with unilateral facial paralysis to recognize and appropriately judge facial expressions and perceive the judgments of others remains underexplored. 45

The likelihood of recovering near-normal facial function after grade VI facial paralysis is low. Procedures, such as the immediate repair of the facial nerve with an interposed donor graft, might improve facial function in patients with partially injured facial nerves. In cases of total section, other procedures can provide better results. ${ }^{46}$ In our study, two patients in the EG and three in the CG underwent surgical reconstruction with a donor graft. At the end of the rehabilitation, all of our patients were referred for surgical consultations to symmetrize and improve their functional recovery when it was deemed necessary. 


\section{COPYRIGHT $^{(\odot)} 2020$ EDIZIONI MINERVA MEDICA}

PAOLUCCI

FACIAL PALSY REHAB WITH MOTOR IMAGERY AND MIRROR THERAPY

\section{Limitations of the study}

A limitation of our study is that we did not have the possibility to control all patients in an appropriate way during the rehabilitation and that not all patients, undergoing neurinoma surgery, showed the EMG/Eng exam.

In our knowledge no study in scientific literature investigated the effect of neurocognitive rehabilitation in facial nerve palsy.

\section{Conclusions}

The integrated use of MT and MI with the classical protocol of mime therapy and the myofascial approach is efficacious in the rehabilitation of FNP, improving facial physical function. Moreover, the EG obtained better results with regard to quality of life and emotional depression. Further studies are needed to determine the predictive factors of the recovery of facial mimicry with respect to the communicative and empathic aspects of facial nerve paresis.

\section{References}

1. Finsterer J. Management of peripheral facial nerve palsy. Eur Arch Otorhinolaryngol 2008;265:743-52.

2. Peitersen E. Bell's palsy: the spontaneous course of 2,500 peripheral facial nerve palsies of different etiologies. Acta Otolaryngol Suppl 2002;(549):4-30.

3. Roob G, Fazekas F, Hartung HP. Peripheral facial palsy: etiology, diagnosis and treatment. Eur Neurol 1999;41:3-9.

4. Ryzenman JM, Pensak ML, Tew JM Jr. Facial paralysis and surgical rehabilitation: a quality of life analysis in a cohort of 1,595 patients after acoustic neuroma surgery. Otol Neurotol 2005;26:516-21, discussion 521. 5. Wilson CM, Ronan SL. Rehabilitation postfacial reanimation surgery after removal of acoustic neuroma: a case study. J Neurol Phys Ther 2010;34:41-9.

6. Paternostro-Sluga T, Herceg M, Frey M. [Conservative treatment and rehabilitation in peripheral facial palsy]. Handchir Mikrochir Plast Chir 2010;42:109-14. German.

7. Azuma T, Nakamura K, Takahashi M, Miyoshi H, Toda N, Iwasaki H, et al. Electroneurography in the acute stage of facial palsy as a predictive factor for the development of facial synkinesis sequela. Auris Nasus Larynx 2018;45:728-31.

8. Pourmomeny AA, Asadi S. Management of synkinesis and asymmetry in facial nerve palsy: a review article. Iran J Otorhinolaryngol 2014;26:251-6.

9. Dobel C, Miltner WH, Witte OW, Volk GF, Guntinas-Lichius O. [Emotional impact of facial palsy]. Laryngorhinootologie 2013;92:9-23. German.

10. van Landingham SW, Diels J, Lucarelli MJ. Physical therapy for facial nerve palsy: applications for the physician. Curr Opin Ophthalmol 2018;29:469-75.

11. Beurskens CH, Heymans PG, Oostendorp RA. Stability of benefits of mime therapy in sequelae of facial nerve paresis during a 1-year period. Otol Neurotol 2006;27:1037-42.

12. Beurskens $\mathrm{CH}$, Heymans PG. Mime therapy improves facial symme- try in people with long-term facial nerve paresis: a randomised controlled trial. Aust J Physiother 2006;52:177-83.

13. Choi HJ, Shin SH. [Effects of a Facial Muscle Exercise Program including Facial Massage for Patients with Facial Palsy]. J Korean Acad Nurs 2016;46:542-51. Korean.

14. Ajimsha MS, Al-Mudahka NR, Al-Madzhar JA. Effectiveness of myofascial release: systematic review of randomized controlled trials. J Bodyw Mov Ther 2015;19:102-12.

15. Lohne V, Bjørnsborg E, Westerby R, Heiberg E. I want to smile. How do individuals with facial paralysis resulting from surgical removal of an acoustic neuroma cope with daily living? Vard Nord Utveckl Forsk 1986;6:311-9.

16. Leong SC, Lesser TH. A national survey of facial paralysis on the quality of life of patients with acoustic neuroma. Otol Neurotol 2015;36:503-9.

17. Zangrando F, Paolucci T, Vulpiani MC, Lamaro M, Isidori R, Saraceni VM. Chronic pain and motor imagery: a rehabilitative experience in a case report. Eur J Phys Rehabil Med 2014;50:67-72.

18. Ramachandran VS, Altschuler EL. The use of visual feedback, in particular mirror visual feedback, in restoring brain function. Brain 2009;132:1693-710.

19. MacIntyre TE, Madan CR, Moran AP, Collet C, Guillot A. Motor imagery, performance and motor rehabilitation. Prog Brain Res 2018;240:141-59.

20. House JW, Brackmann DE. Facial nerve grading system. Otolaryngol Head Neck Surg 1985;93:146-7.

21. Reitzen SD, Babb JS, Lalwani AK. Significance and reliability of the House-Brackmann grading system for regional facial nerve function. Otolaryngol Head Neck Surg 2009;140:154-8.

22. Schulz KF, Altman DG, Moher D; CONSORT Group. CONSORT 2010 Statement: updated guidelines for reporting parallel group randomised trials. BMC Med 2010;8:18.

23. Evans RA, Harries ML, Baguley DM, Moffat DA. Reliability of the House and Brackmann grading system for facial palsy. J Laryngol Otol 1989;103:1045-6.

24. Pavese C, Tinelli C, Furini F, Abbamonte M, Giromini E, Sala V, et $a l$. Validation of the Italian version of the Sunnybrook Facial Grading System. Neurol Sci 2013;34:457-63.

25. Kahn JB, Gliklich RE, Boyev KP, Stewart MG, Metson RB, McKenna MJ. Validation of a patient-graded instrument for facial nerve paralysis: the FaCE scale. Laryngoscope 2001;111:387-98.

26. Henstrom DK, Lindsay RW, Cheney ML, Hadlock TA. Surgical treatment of the periocular complex and improvement of quality of life in patients with facial paralysis. Arch Facial Plast Surg 2011;13:125-8.

27. Borodic G, Bartley M, Slattery W, Glasscock M, Johnson E, Malazio $\mathrm{C}$, et al. Botulinum toxin for aberrant facial nerve regeneration: doubleblind, placebo-controlled trial using subjective endpoints. Plast Reconstr Surg 2005;116:36-43.

28. Beck AT, Steer RA, Brown GK. Manual for the Beck Depression Inventory second edition (BDI-II). The Psychological Corporation, 1996.

29. Richter P, Werner J, Heerlein A, Kraus A, Sauer H. On the validity of the Beck Depression Inventory. A review. Psychopathology 1998;31:160-8. 30. Osgood CE. Dimensionality of the semantic space for communication via facial expressions. Scand J Psychol 1966;7:1-30.

31. Beurskens $\mathrm{CH}$, Heymans PG. Positive effects of mime therapy on sequelae of facial paralysis: stiffness, lip mobility, and social and physical aspects of facial disability. Otol Neurotol 2003;24:677-81.

32. Pereira LM, Obara K, Dias JM, Menacho MO, Lavado EL, Cardoso JR. Facial exercise therapy for facial palsy: systematic review and metaanalysis. Clin Rehabil 2011;25:649-58.

33. Baricich A, Cabrio C, Paggio R, Cisari C, Aluffi P. Peripheral facial nerve palsy: how effective is rehabilitation? Otol Neurotol 2012;33:1118-26. 


\section{COPYRIGHT $^{\circledR} 2020$ EDIZIONI MINERVA MEDICA}

34. Coulson SE, Croxson GR, Adams RD, O'Dwyer NJ. Reliability of the "Sydney," "Sunnybrook," and "House Brackmann" facial grading systems to assess voluntary movement and synkinesis after facial nerve paralysis. Otolaryngol Head Neck Surg 2005;132:543-9.

35. Oostra KM, Oomen A, Vanderstraeten G, Vingerhoets G. Influence of motor imagery training on gait rehabilitation in sub-acute stroke: A randomized controlled trial. J Rehabil Med 2015;47:204-9.

36. Lisalde-Rodríguez ME, Garcia-Fernández JA. [Mirror therapy in hemiplegic patient]. Rev Neurol 2016;62:28-36. Spanish.

37. Abolfazli M, Lajevardi L, Mirzaei L, Abdorazaghi HA, Azad A, Taghizadeh G. The effect of early intervention of mirror visual feedback on pain, disability and motor function following hand reconstructive surgery: a randomized clinical trial. Clin Rehabil 2019;33:494-503.

38. Darbois N, Guillaud A, Pinsault N. Do Robotics and Virtual Reality Add Real Progress to Mirror Therapy Rehabilitation? A Scoping Review. Rehabil Res Pract 2018;2018:6412318.

39. Nellis JC, Ishii M, Byrne PJ, Boahene KD, Dey JK, Ishii LE. Association Among Facial Paralysis, Depression, and Quality of Life in Facial Plastic Surgery Patients. JAMA Facial Plast Surg 2017;19:190-6.

40. Spencer CR, Irving RM. Causes and management of facial nerve palsy. Br J Hosp Med (Lond) 2016;77:686-91.
41. Chen J, Yang LQ, Zhang ZJ, Ma WT, Wu XQ, Zhang XR, et al. The association between the disruption of motor imagery and the number of depressive episodes of major depression. J Affect Disord 2013;150:337-43.

42. Avanzino L, Gueugneau N, Bisio A, Ruggeri P, Papaxanthis C, Bove M. Motor cortical plasticity induced by motor learning through mental practice. Front Behav Neurosci 2015;9:105.

43. Brooker J, Burney S, Fletcher J, Dally M. A qualitative exploration of quality of life among individuals diagnosed with an acoustic neuroma. $\mathrm{Br}$ J Health Psychol 2009;14:563-78.

44. Konnerth V, Mohr G, von Piekartz H. [Emotion Recognition in Patients with Peripheral Facial Paralysis - A Pilot Study]. Rehabilitation (Stuttg) 2016;55:19-25. German.

45. Korb S, Wood A, Banks CA, Agoulnik D, Hadlock TA, Niedenthal PM. Asymmetry of Facial Mimicry and Emotion Perception in Patients With Unilateral Facial Paralysis. JAMA Facial Plast Surg 2016;18:222-7.

46. Pardo-Maza A, Lassaletta L, González-Otero T, Roda JM, Moraleda $\mathrm{S}$, Arbizu Á, et al. Evolution of Patients With Immediate Complete Facial Paralysis Secondary to Acoustic Neuroma Surgery. Ann Otol Rhinol Laryngol 2016;125:495-500.

Conflicts of interest.-The authors certify that there is no conflict of interest with any financial organization regarding the material discussed in the manuscript. Acknowledgements.-The authors would like to thank Andrea Melchionna, Gloria del Grosso, and Giovanni Licari, students of physiotherapy at S. Camillo Forlanini and S. Filippo Neri Hospital, for their collaboration. They are also grateful to the patients enrolled, who have made this this study possible.

Article first published online: March 27, 2019. - Manuscript accepted: March 26, 2019. - Manuscript revised: March 25, 2019. - Manuscript received: March $1,2019$. 